\title{
Correction to: Reversal of homocysteine- induced neurotoxicity in rat hippocampal neurons by astaxanthin: evidences for mitochondrial dysfunction and signaling crosstalk
}

Xian-jun Wang ${ }^{1}$, Wang Chen ${ }^{1}$, Xiao-ting Fu², Jin-kui Ma ${ }^{3}$, Mei-hong Wang ${ }^{4}$, Ya-jun Hou' ${ }^{2}$ Da-chen Tian', Xiao-yan $\mathrm{Fu}^{2}$ and Cun-dong Fan $\mathbb{1}^{2}$

\section{Correction to: Cell Death Discovery (2018)} https://doi.org/10.1038/s41420-018-0114-x published online 22 October 2018

The Article contains an error in Fig. 2a. Two images in Fig. 2a (control group and ATX-treated group) were

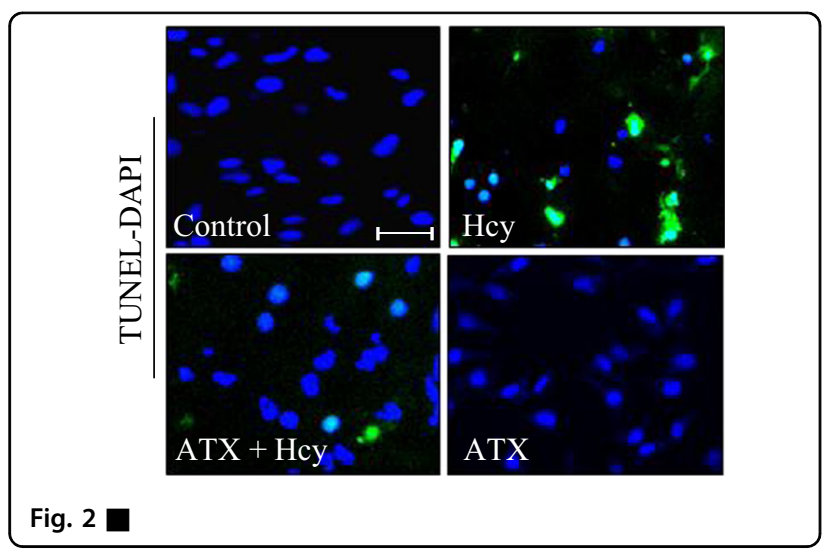

inadvertently duplicated. The control group and ATXtreated group both showed no significant cell apoptosis, the experimenter misunderstood that the same image should be used. (Note: A similar error by the same experimenter was also found in Fig. $2 \mathrm{C}$ in another publication "Natural borneol is a novel chemosensitizer that enhances temozolomide-induced anticancer efficiency against human glioma by triggering mitochondrial dysfunction and reactive oxide species-mediated oxidative damage", https://doi.org/10.2147/OTT.S174498.

The correct Fig. 2a appears below

Published online: 01 March 2019

Correspondence: X-y. Fu (txyfu66@163.com) or C-d. Fan (tcdfan66@163.com)

'Department of Neurology, People's Hospital of Linyi Affiliated to Qingdao

University, 276000 Linyi, Shandong, China

${ }^{2}$ School of Basic Medicine, Taishan Medical University, 271000 Taian,

Shandong, China

${ }^{3}$ Faculty of Bioresource Sciences, Akita Prefectural University, 241-438

Kaidobata-Nishi, Shimoshinjo-Nakano, 010-0195 Akita-shi, Akita, Japan

${ }^{4}$ Department of Neurology, People's Hospital of Yishui, 276400 Linyi,

Shandong, China

(c) (i) Open Access This article is licensed under a Creative Commons Attribution 4.0 International License, which permits use, sharing, adaptation, distribution and reproduction in any medium or format, as long as you give appropriate credit to the original author(s) and the source, provide a link to the Creative Commons license, and indicate if changes were made. The images or other third party material in this article are included in the article's Creative Commons license, unless indicated otherwise in a credit line to the material. If material is not included in the article's Creative Commons license and your intended use is not permitted by statutory regulation or exceeds the permitted use, you will need to obtain permission directly from the copyright holder. To view a copy of this license, visit http://creativecommons.org/licenses/by/4.0/. 